\title{
Trichomonacidal Activity of 3,3'-Diindolylmethane (DIM) Is Additive to Metronidazole (MTZ) In Vitro, Supporting Future Oral/Topical Use ${ }^{+}$
}

\author{
Alexandra Ibáñez-Escribano ${ }^{1, *}$, Leyre Pernaute Lau ${ }^{1}$, Juan José Nogal-Ruiz ${ }^{1}$, \\ Alicia Gómez-Barrio ${ }^{1}$, Jose Antonio Escario ${ }^{1}$ and Michael A. Zeligs ${ }^{2}$ \\ 1 Departamento de Parasitología, Facultad de Farmacia, Universidad Complutense de Madrid, \\ Pza. Ramón y Cajal s/n, 28040 Madrid, Spain; lpernaut@ucm.es (L.P.L.); jjnogalr@ucm.es (J.J.N.-R.); \\ agbarrio@ucm.es (A.G.-B.); escario@ucm.es (J.A.E.) \\ 2 BioResponse LLC., P.O. Box 288 Boulder, CO 80306, USA; zeligsmd@bioresponse.com \\ * Correspondence: alexandraibanez@ucm.es \\ + Presented at the 1st Molecules Medicinal Chemistry Symposium, Barcelona, Spain, 8 September 2017.
}

Published: 19 October 2017

New, safe, well tolerated, and versatile anti-trichomonal agents for oral and topical use are needed to combat spreading resistance of Trichomonas vaginalis to metronidazole (MTZ). Diindolylmethane (DIM) is a non-toxic, cruciferous indole under pharmaceutical development for treatment of cervical and prostatic pre-cancers. Present work reports anti-trichomonal activity of DIM with IC 50 hundreds of times below the DIM concentration provided in a clinic-ready, sustainedrelease, vaginal-topical formulation (BR-DIM-VC ${ }^{\mathrm{TM}} 2 \%$ ) which has passed vaginal tolerance testing in rabbits. Present in vitro findings against $T$. vaginalis exhibit additive effects of DIM with MTZ, significantly reducing the $\mathrm{IC}_{50}$ for MTZ $(p<0.05)$. Combinatorial activity with MTZ was demonstrated using DIM dissolved in DMSO and in a novel self-emulsifying lipid-based formulation, BR-9001, showing a statistically significant enhanced effect of BR-9001 over DIM (DMSO) $(p<0.05)$. Improved bio-delivery of DIM from BR-9001 confirmed DIM's concentration-dependent trichomonacidal activity. Performed in triplicate, the anti-parasitic results are: $\mathrm{IC}_{50}$ DIM-DMSO $=91.8 \mu \mathrm{M}, \mathrm{IC}_{50}$ BR-9001 $=30.65$ $\mu \mathrm{M} *, \mathrm{IC}_{50} \mathrm{MTZ}=2.34 \mu \mathrm{M}, \mathrm{IC}_{50} \mathrm{MTZ}(0.75 \mathrm{uM})+\operatorname{DIM}(37.5 \mathrm{uM})=1.6 \mu \mathrm{M} *$ and $\mathrm{IC}_{50} \mathrm{MTZ}(0.75 \mathrm{uM})+\mathrm{BR} 9-001(37.5 \mathrm{uM})=0.8 \mu \mathrm{M} *, *$ $p<0.05$.

Considering the nonexistent therapeutic alternatives for trichomonosis treatment in patients with hypersensitivity to 5-nitroimidazoles or against resistant cases, the combined use of DIM + MTZ for oral and topical administration provides a promising new therapeutic opportunity.

Acknowledgments: This work was supported by grants from Spanish Ministerio de Economía y Competitividad (SAF2015-66690-R) and a contract between, BioResponse, L.L.C., and the research group 911120 of the Universidad Complutense de Madrid (UCM).

Author Contributions: M.A.Z. provided reagents and contributed to the analysis of the results. L. P.-L. participated in performance of the biological assays under the supervision of the rest of the UCM members. J.J. N.-R., J.A.E, and A. G.-B. participated in the evaluation of the biological results. A. I.-E. was responsible for the design and development of the parasitic assays, interpretation of data, and drafting the manuscript. Authors give final approval of the version to be submitted and any revised version.

Conflicts of Interest: M.A.Z is a stockholder in BioResponse, LLC. L.P.-L, J.J.N.-R., J.A.E., A.G.-B., and A.I.E. declare no conflicts of interest.

(C) 2017 by the authors. Licensee MDPI, Basel, Switzerland. This article is an open access article distributed under the terms and conditions of the Creative Commons Attribution (CC BY) license (http://creativecommons.org/licenses/by/4.0/). 